Defence Science Journal, Vol. 57, No. 6, November 2007, pp. 865-876

(C) 2007, DESIDOC

\title{
Modelling, Simulation, and Analysis of HAL Bangalore International Airport
}

\author{
P. Lathasree, T. Senthilkumar, and Padma Madhuranath \\ National Aerospace Laboratories, Bangalore-560 017
}

\begin{abstract}
Air traffic density in India and the world at large is growing fast and posing challenging problems. The problems encountered can be parameterized as flight delay, workload of air traffic controllers and noise levels in and around aerodromes. Prediction and quantification of these parameters aid in developing strategies for efficient air traffic management. In this study, the method used for quantifying is by simulation and analysis of the selected aerodrome and air space. This paper presents the results of simulation of HAL Bangalore International Airport, which is used by civil as well as military aircraft. With the test flying of unscheduled military aircraft and the increase in the civil air traffic, this airport is hitting the limit of acceptable delay. The workload on air traffic controllers is pushed to high during peak times. The noise contour prediction, especially for the test flying military aircraft is sounding a wake up call to the communities living in the vicinity of the Airport.
\end{abstract}

Keywords: Modelling, simulation, ground delay, air delay, controller workload, air traffic, noise prediction, military aircraft

\section{INTRODUCTION}

The most congested airports in India are at Mumbai, New Delhi, and Bangalore. Bangalore has attracted a large number of international agencies to start industries and research centres. As a consequence, one of the hard hit services of this city is the HAL Bangalore International Airport (HBIA) having to cope with unprecedented air traffic growth of passenger, cargo and military aircraft. Unlike other civil aerodromes, HBIA has a big challenge of coping with traffic from flight testing of military airplanes, the flight schedules of which are not as well planned as the civil air traffic. The noise pollution from defence airplanes is very high as seen from the results of the studies presented here.
The forecast of air traffic growth in India from 2001-2006 has been 5 per cent for domestic passengers and cargo traffic. The forecast for the international passenger traffic has been 6 per cent while for international cargo it has been 7.5 per cent ${ }^{1}$. The ATCs in all the busy airports in India have to cope with high stress. Those people living close to the airports are beginning to hit the limit of annoyance due to noise pollution caused by increased air traffic. What can be done to avoid or reduce the workload of ATCs, delay at airports and noise levels near aerodromes? One of the prevalent methods in any technology development programmes is to resort to simulation. Simulation of air traffic helps in predicting delays, ATC workloads, and noise levels near aerodromes besides a host of other factors.

Received 31 August 2006, revised 4 June 2007 
At National Aerospace Laboratories (NAL), $a b$ initio simulation facility has been set up to initially address the above three problems for Indian air traffic, airports, and airspace. The results of simulation studies for HBIA are presented in this paper $^{2}$. From the simulation of HBIA, ground and air delay study and analyses have been carried out. The ATC workload is also affected with the rapid growth of air traffic. With growth of air traffic, aircraft noise is having an impact on communities living in and around the airports. At NAL, noise predictions have been carried out around HBIA using air traffic simulation. The results from the simulation give good indications to ATCs, airport designers and authorities who need to minimise controller workload, reduce delay, and ensure safe noise levels in the vicinity of airports.

\section{MODELLING AND SIMULATION METHODOLOGY}

The four main functions of an air traffic simulator are: (i) modelling of airfield and airspace structure, (ii) creating a schedule for the air traffic, (iii) simulating airports with air routes connecting these to other airports, and (iv) visualising the flights by running an animated simulation.

\subsection{Modelling}

Airfield and airspace models are two essential constituents. The airfield model consists of runways, departure queues for holding and sequencing aircraft departing on runways, taxiways for aircraft movement between gates and runways, and dynamic single direction (DSD) paths. The airspace model consists of airports with associated zones of control, named aerodromes, and a set of airways connecting pairs of airports. Airspace may contain one or more airways, which are corridors through the airspace, originating and ending directly above the airports.

\subsection{Simulation}

The study of air traffic generally spans 24 hours each day. It is convenient to have time scaled simulation where the time scale can range from 1 to 100. This enables seeing the reality of one hour happening in one minute or less, and hence the usage of the term fast-time simulation. Figure 1 shows a block schematic of the fast-time simulation model. The fast-time simulation has a discrete-event stochastic model in the software ${ }^{3}$. It is a gate-to-gate simulation model where inputs to the fast-time simulation are airfield and airspace models, ATC procedures, and the flight schedules. Using the flight schedules, the simulation is carried out using point mass flight simulation to obtain the results as output. In this study, three output, namely, flight delay, controller workload, and noise contours are analysed.

\section{DELAY AT AIRPORTS AND AIRSPACE}

Delay is one of the principal measures of performance of ATM systems. Delay is defined as

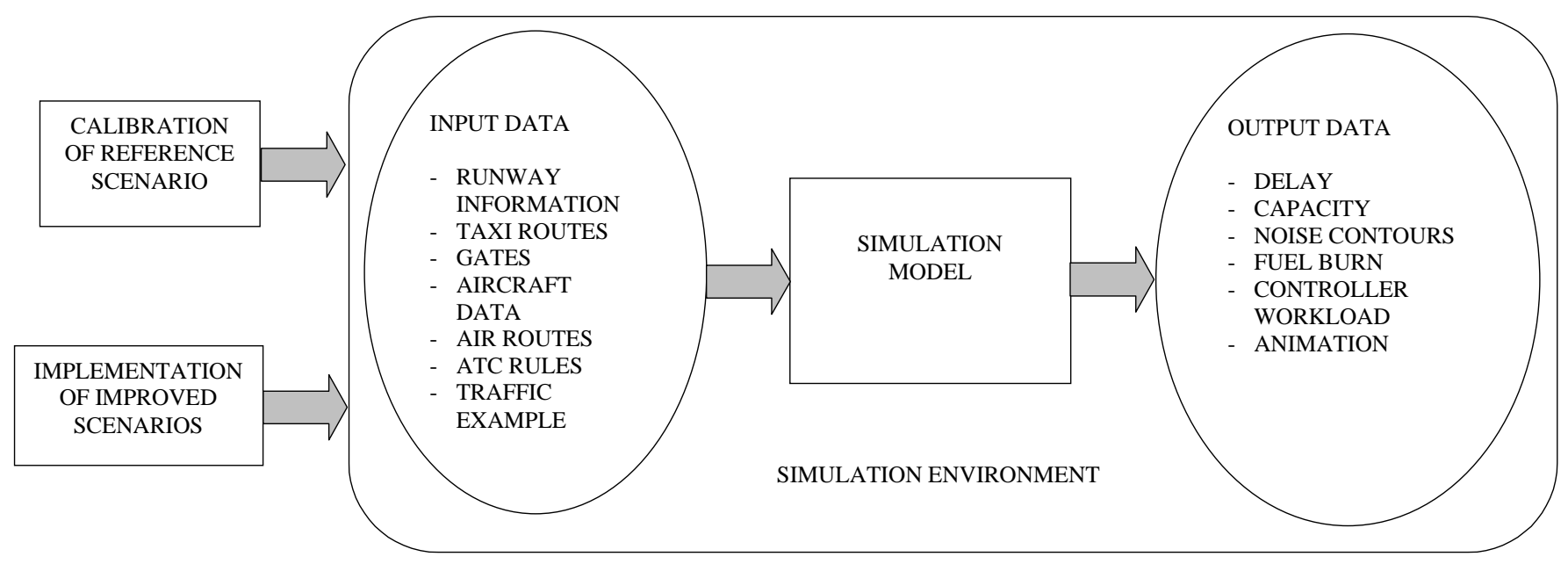

Figure 1. Block schematic of fast-time simulation model. 
the difference between the planned and actual time of operation like arrival and departure of a particular aircraft ${ }^{4}$. Delay can be easily predicted using fast-time simulation. It is necessary to distinguish between two types of delay namely ground delay and air delay.

Ground delay is the difference between the planned and actual time of arrival/departure of an aircraft when the aircraft is on the ground particularly on runways, taxiways, and at gates. This can occur between the runway and the gate due to taxiway congestion, runway crossings and separation requirements due to wake turbulence, push back delay, taxi speed variation or waiting in departure queue.

Air delay is the difference between the planned and actual time of arrival/departure of an aircraft when the aircraft is in the air. Air delay occurs once the aircraft is airborne till it touches down due to wind conditions en-route and separation requirements for conflict- free flight in high traffic. The flight schedules give the planned time of arrival/ departure of an aircraft. Taking into consideration current simulated weather, simulated wake turbulence, simulated ATC procedures that take care to ensure conflict-free traffic, both in the air and on the ground, the fast-time simulation generates the exact time of arrival and departure of all aircraft. The

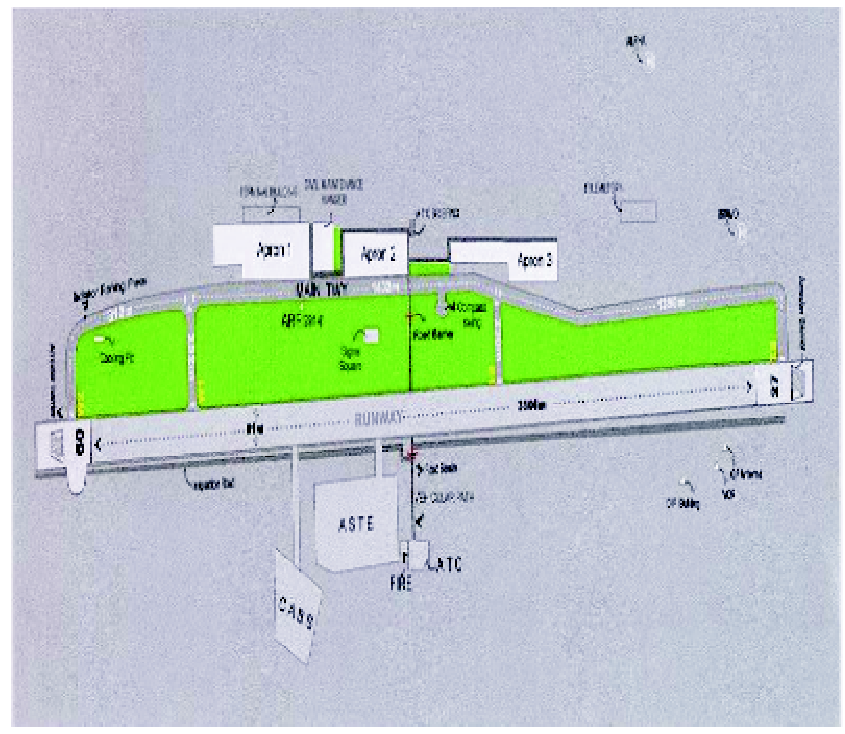

Figure 2. Airfield model-HBIA. aircraft delay constituted of ground and air delay, comes out as a by-product of the simulation.

The progression of air and ground delay of each aircraft movement has been computed and plotted as a function of simulation time in $24 \mathrm{~h}$ window. The plot contains the statistical information like average delay and standard deviation. The delay studies for HBIA and Mumbai International Airport have been carried out for the domestic flight schedules during $2002^{5}$. Simulation studies have been conducted during 2005 for HBIA and the corresponding results are discussed.

\subsection{HBIA Simulation Studies}

Figures 2 and 3 show the airfield and airspace models respectively. These are used for modelling and simulation of HBIA. From the flight schedules supplied by ATC-Bangalore, Thursday is found to be a busy day, and hence, the delay studies were carried out for this day. These flight schedules exclude the unscheduled test flying military aircraft for which the required proper information is not available. Figures 4(a) and 4(b) show the progression of ground and air delay for the 250 aircraft movements as on Thursday, 24 ${ }^{\text {th }}$ November 2005. From the figures, the maximum ground delay and air delay are found to be $4.5 \mathrm{~min}$ and $9.5 \mathrm{~min}$, respectively. The average ground and airspace delay are $22 \mathrm{~s}$ and $61 \mathrm{~s}$ respectively. The average delay is well within the stipulated maximum value of $4-5 \min ^{6,7}$.

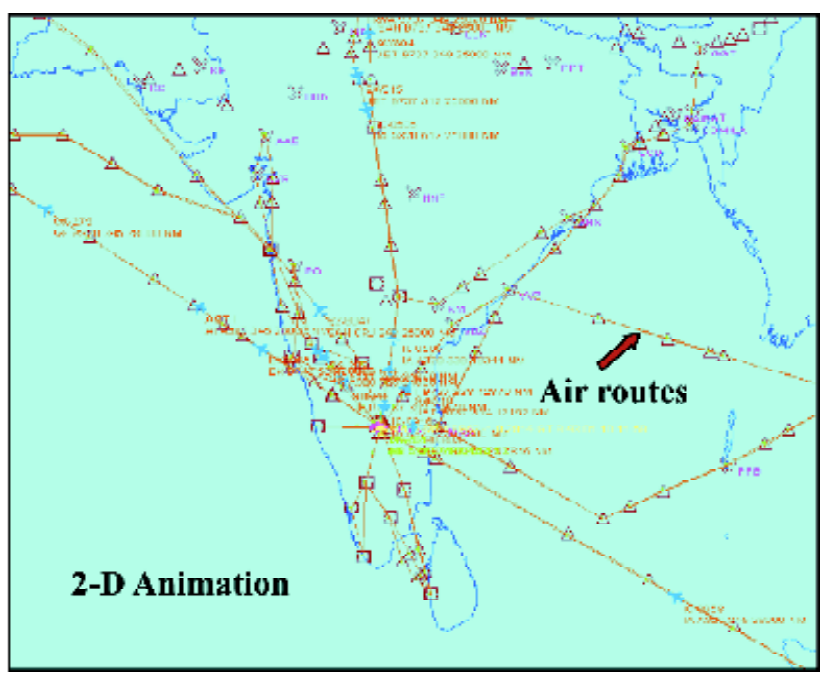

Figure 3. Airspace scenario-HBIA. 
Table 1 shows the comparison of air traffic at HBIA during 2005. From the table, the average ground and airspace delay are found to be gradually increasing with increasing air traffic.

The fast-time simulation can predict the delays for the futuristic scenario. With 10 per cent of cloning plus the present traffic, the maximum ground delay is found to be $8.5 \mathrm{~min}$ and the maximum airspace delay is found to be $25 \mathrm{~min}$ as can be seen from Figs 5(a) and 5(b). The average ground delay and airspace delay are $39 \mathrm{~s}$ and $1 \mathrm{~min} 43 \mathrm{~s}$ respectively. It is known that the maximum allowable delay is

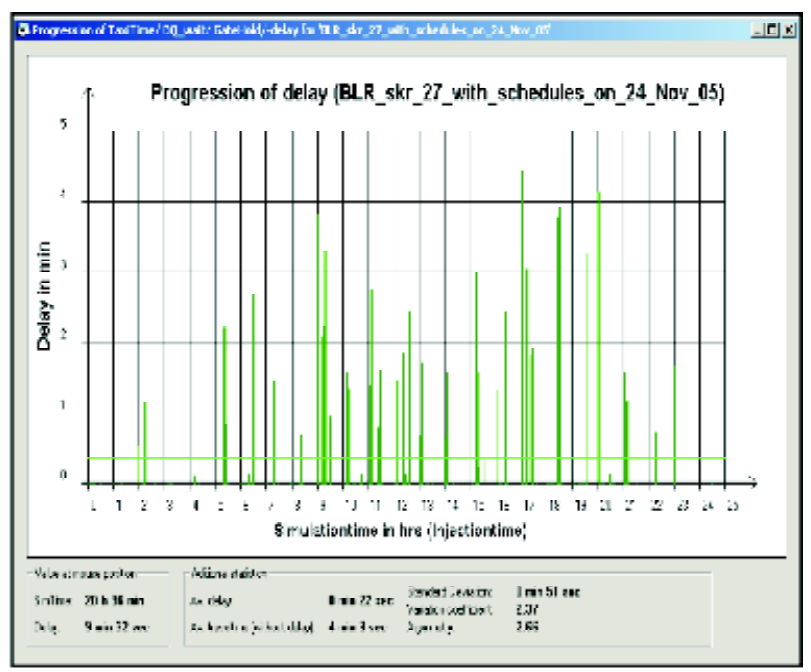

(a)

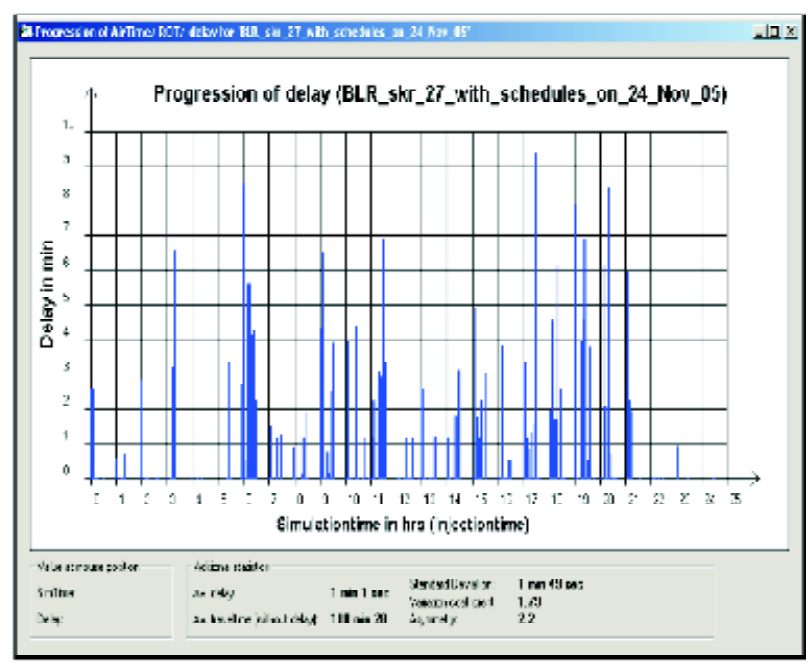

(b)

Figure 4. Progression of delay with current traffic $\mathbf{- 2 5 0}$ movements/day: (a) total ground movements delay, and (b) total airspace movements delay
$20 \min ^{7}$ and with 10 per cent cloning, the delay is reaching the maximum limit. This indicates that one needs to adopt strategies to reduce delay to accommodate the growing traffic.

\section{CONTROLLER WORKLOAD}

In the current air transport scenario, the air traffic is increasing at a rapid pace, and hence, causing the airspace congestion. Figure 6 shows a typical air transport schematic which highlights the controller workload problems. Controller workload is the effort expended by the controller to manage

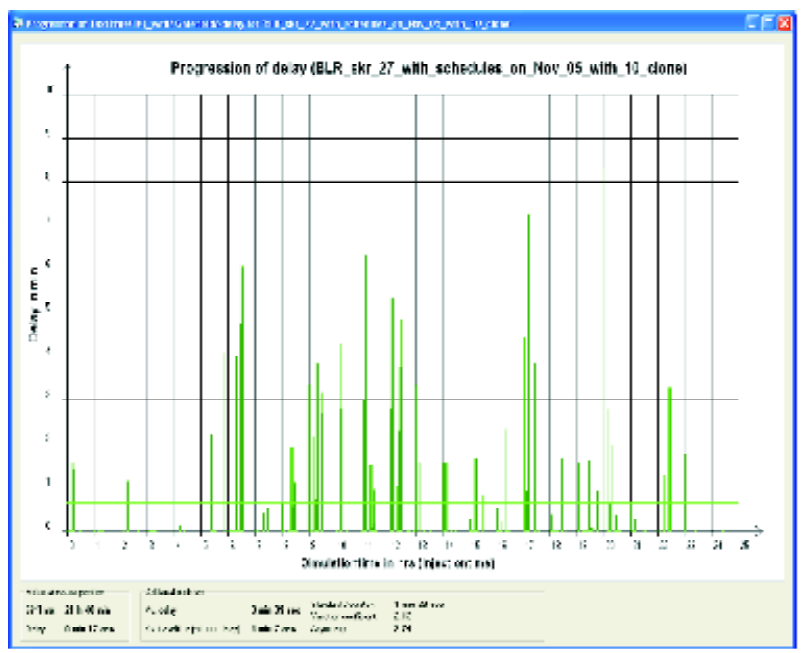

(a)

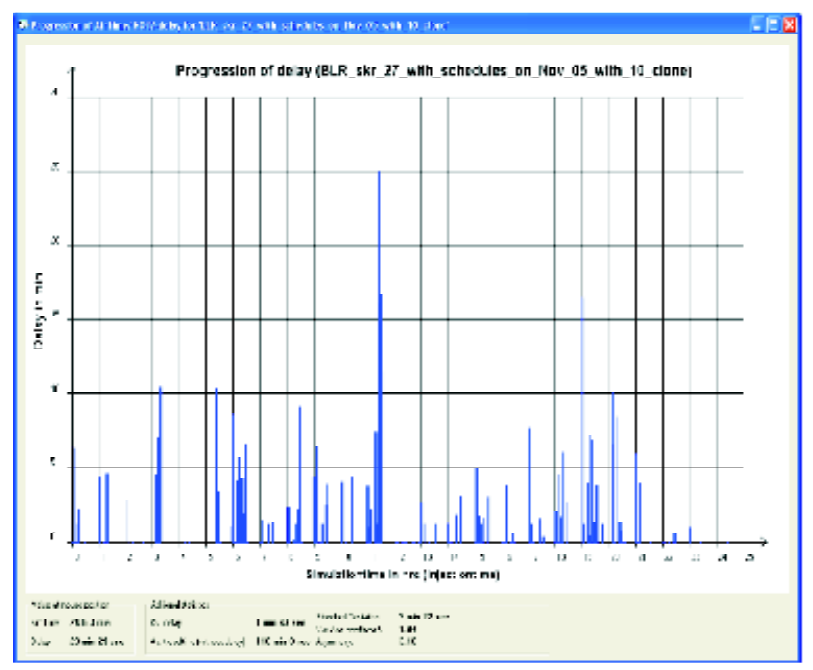

(b)

Figure 5. Progression of delay with $10 \%$ cloning of current traffic - 275 movements/day: (a) total ground movements delay, and (b) total airspace movements delay. 
Table 1. Comparison of traffic at HBIA during 2005

\begin{tabular}{lccc}
\hline & $\begin{array}{c}\mathbf{1 2}^{\text {th }} \mathbf{M a y} \\
\mathbf{2 0 0 5}\end{array}$ & $\begin{array}{c}\mathbf{1 1}^{\text {th }} \text { August } \\
\mathbf{2 0 0 5}\end{array}$ & $\begin{array}{c}\mathbf{2 4}^{\text {th }} \text { Nov. } \\
\mathbf{2 0 0 5}\end{array}$ \\
\hline No. of movements/day & 209 & 220 & 250 \\
Air delay (min) & 7 max. & 9 max. & 10 max. \\
$\begin{array}{l}\text { Ground delay (min) } \\
\begin{array}{l}\text { Average ground delay } \\
\text { (s) }\end{array}\end{array}$ & 4 max. & 6 max. & 5 max. \\
\begin{tabular}{l} 
Average air delay (s) \\
\hline
\end{tabular} & 40 & 21 & 22 \\
\hline
\end{tabular}

air traffic events. A measure of air traffic controller workload is needed to evaluate the effects of new systems and procedures on individual ATCs and on the ATC systems as a whole. Controller workload consists of planning, coordinating, deciding, communicating, and handling unanticipated unforeseen situations.

The air traffic control team consists of planning controller and tactical controller. The prime duty of the planning controller is to agree entry and exit conditions with adjacent sectors. The planning controller compares the data abstracted from flight plans and presented on the flight strips to decide height changes for aircraft to avoid close approaches between aircraft. The main task of the tactical

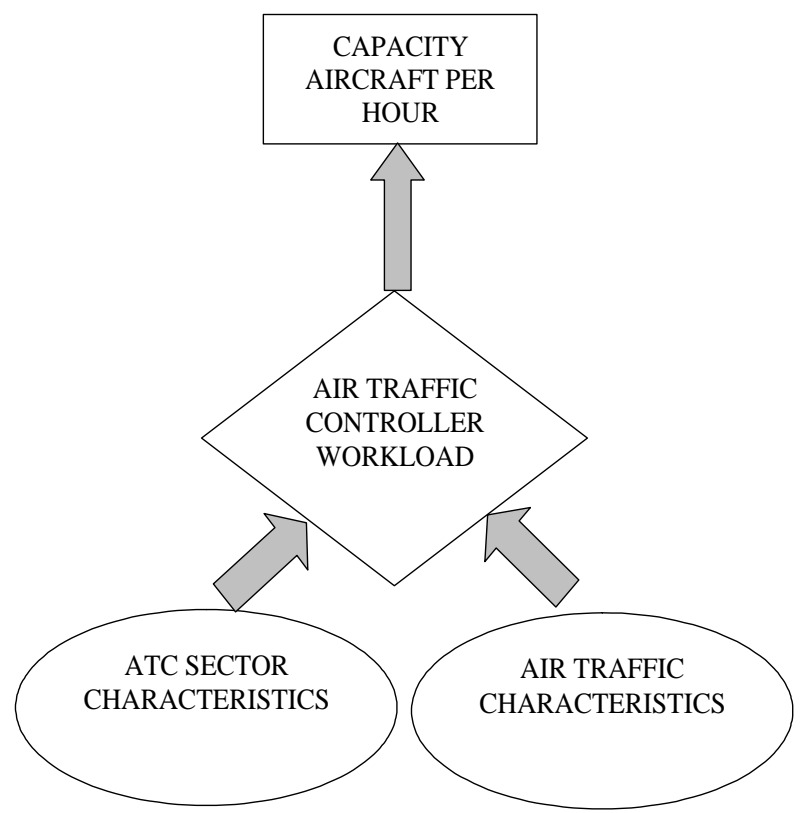

Figure 6. Air transport schematic with controller workload. controller is to maintain the specified aircraft separation distances by watching the radar. Depending on the complexity of air routes in the sector, tactical controller manages 8 to 20 aircraft at the same time. Figure 7 shows that the important factors affecting air traffic controller workload are sector and air traffic characteristics. The factors affecting air traffic and sectors are many and are given ${ }^{8}$ in Table 2.

Controller workload is described by three types, namely, monitoring workload for monitoring of aircraft in the controllers sector; resolution workload for resolution induced by the resolution of conflicts; and co-ordination workload for negotiation between adjacent controllers.

Using the fast-time simulation software ${ }^{9}$, monitoring workload can be measured. Monitoring workload will be an objective measure for the controller workload. Based on the Sector definition and the flight schedules, simulation provides the information on monitoring workload, e.g., number of aircraft movements per hour, number of heading changes, number of altitude changes, and number of speed changes, etc.

Figure 8 shows the monitoring workload for the months of January and November 2005 in the Bangalore sector, obtained from the simulation studies. This figure indicates the number of aircraft controlled by the controller for a $24 \mathrm{~h}$ simulation. It is noticed that the number of aircraft handled between 0800 and 0900 hours is maximum and found to be around 21 movements. These movements include the test

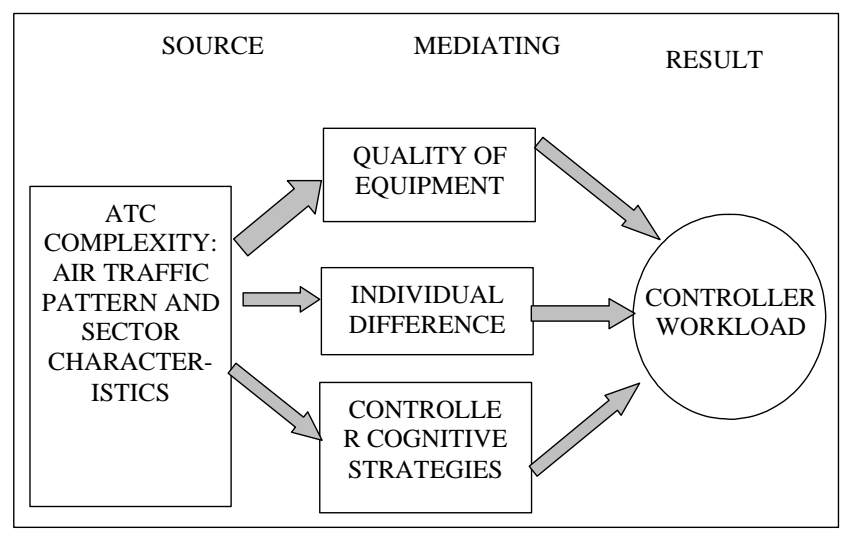

Figure 7. Controller workload factors. 
Table 2. Factors affecting air traffic pattern and sector

\begin{tabular}{ll}
\hline Factors affecting air traffic & Factors affecting sectors \\
\hline Total number of aircraft & Sector Size \\
Peak hourly count & Sector shape \\
Traffic mix & Boundary location \\
Climbing/descending aircraft & $\begin{array}{c}\text { Number of Intersection } \\
\text { points }\end{array}$ \\
Aircraft speeds & Number of flight levels \\
Horizontal separation standards & $\begin{array}{c}\text { Number of facilities } \\
\text { Vertical separation standards }\end{array}$ \\
Number of entry and exit \\
points \\
sector & Airway configuration \\
Total flight time in sector & Proportion of unidirectional \\
& routes \\
Average flight direction & Number of surrounding \\
\end{tabular}

flying aircraft and the scheduled flights. It is noticed that increase in traffic from January to November 2005 is 35 per cent.

\section{NOISE CONTOURS FOR AERODROME PLANNING}

Noise pollution is one of the greatest threats in aviation. As air traffic is growing at a fast pace, the level of noise encountered around aerodromes during the course of each day is increasing. Noise contour predictions are useful for airport operators, for state civic amenity planners, and for citizens involved in noise-control planning. It enables identification of incompatible land uses around aerodromes. The goal of simulation/prediction of noise is to enable the relevant authorities to develop strategies to minimise aerodrome noise impact on local communities. One important issue is to find

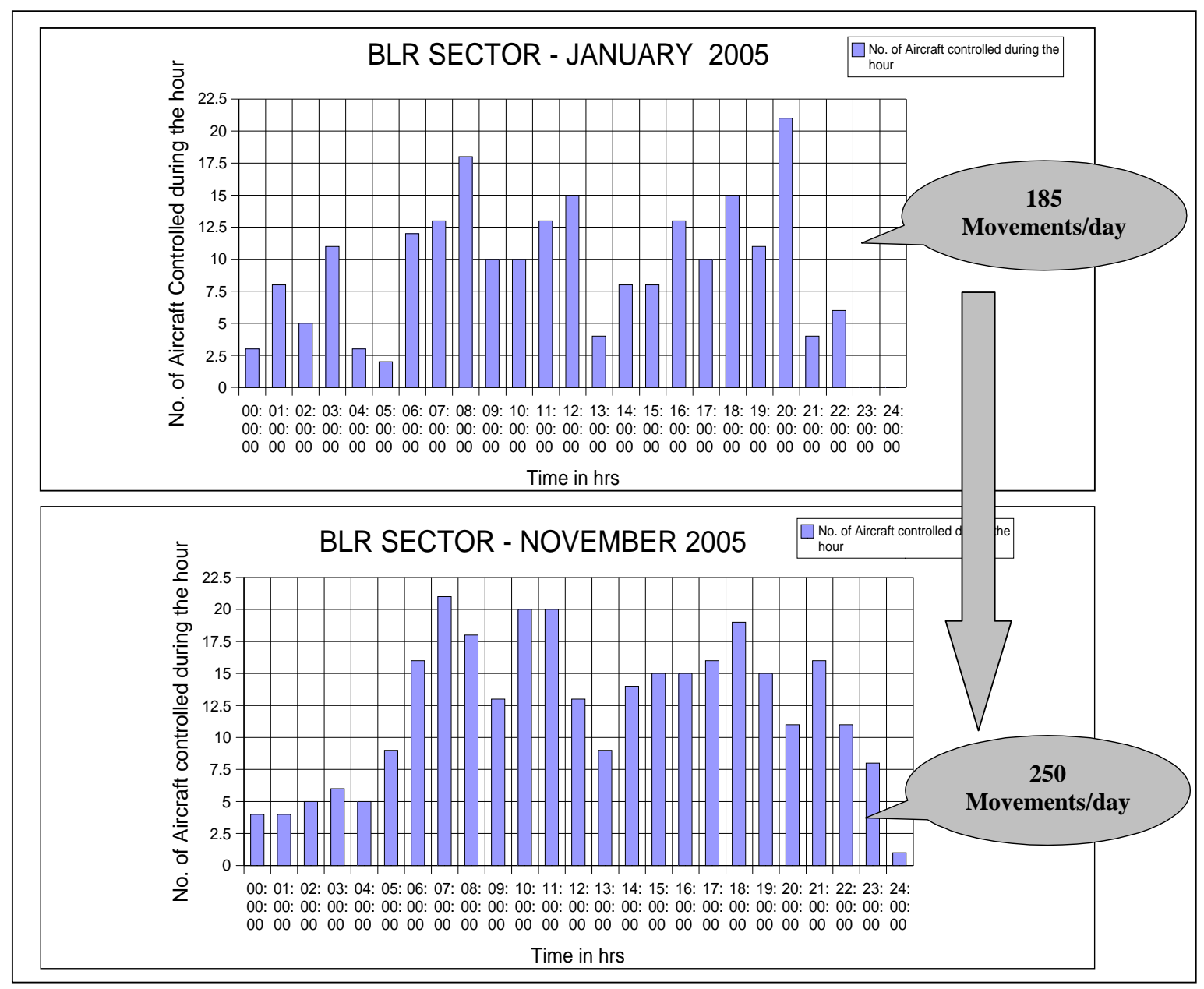

Figure 8. Monitoring workload for the Bangalore sector. 
a suitable method to predict noise levels in and around aerodromes considering the air traffic and the types of aircraft arriving, departing and flying over a particular aerodrome. A block schematic of the noise prediction model is shown in Fig. 9.

\subsection{Noise Model}

Federal Aviation Administration (FAA) Office of Environment and Energy has developed the integrated noise model (INM). It is widely used by the civil aviation community for evaluating aircraft noise impacts in the vicinity of airports. It is used in the US for Federal Aviation Regulation (FAR) part 150-noise compatibility planning. It has the capability to analyse noise in post-simulation environments ${ }^{10}$. For these studies, INM has been used. The only way to convey information to communities around an airport is to compute potential noise levels before constructing a facility. Noise prediction is a tedious process for real airports as there are too many airplanes and tracks that need to be analysed in determining the noise at a point on the ground.

The goal of noise compatibility program is to reduce the size of the area and distance from the airport where loud airport-generated noises are heard. The airport owner can analyse certain alternatives to determine if these are appropriate for the individual airport and for the community.
These alternatives include, but are not limited to airport operational changes. In addition, the construction of barriers and acoustical shielding including soundproofing of public buildings will be beneficial to cope with high noise levels.

\subsection{Noise Metrics}

The noise metrics commonly used for a single event are: (i) A-weighted sound exposure level (SEL) and (ii) A-weighted maximum sound level (LAMAX).

The noise metrics commonly used for multiple events are day-night average sound level (DNL), equivalent sound level (LAEQ) and community noise equivalent level (CNEL). The three noise metrics important from the community noise point of view, namely SEL, LAMAX and DNL have been discussed ${ }^{11,12}$.

\subsubsection{A-weighted Sound Exposure Level}

The sound exposure level (SEL) is the sound produced at a fixed location near the ground by an airplane operation. It is defined as the total sound energy from an overflight squashed into one second. Mathematically, if $P$ is the a-weighted sound pressure, $P_{0}$ is the reference pressure of $20 \mu \mathrm{Pa}$ and $T$ is the reference time of $1 \mathrm{~s}$, then, the A-weighted sound exposure level $L_{A E}$ from the time $t_{1}$ to $t_{2}$ is given by Eqn (1) as

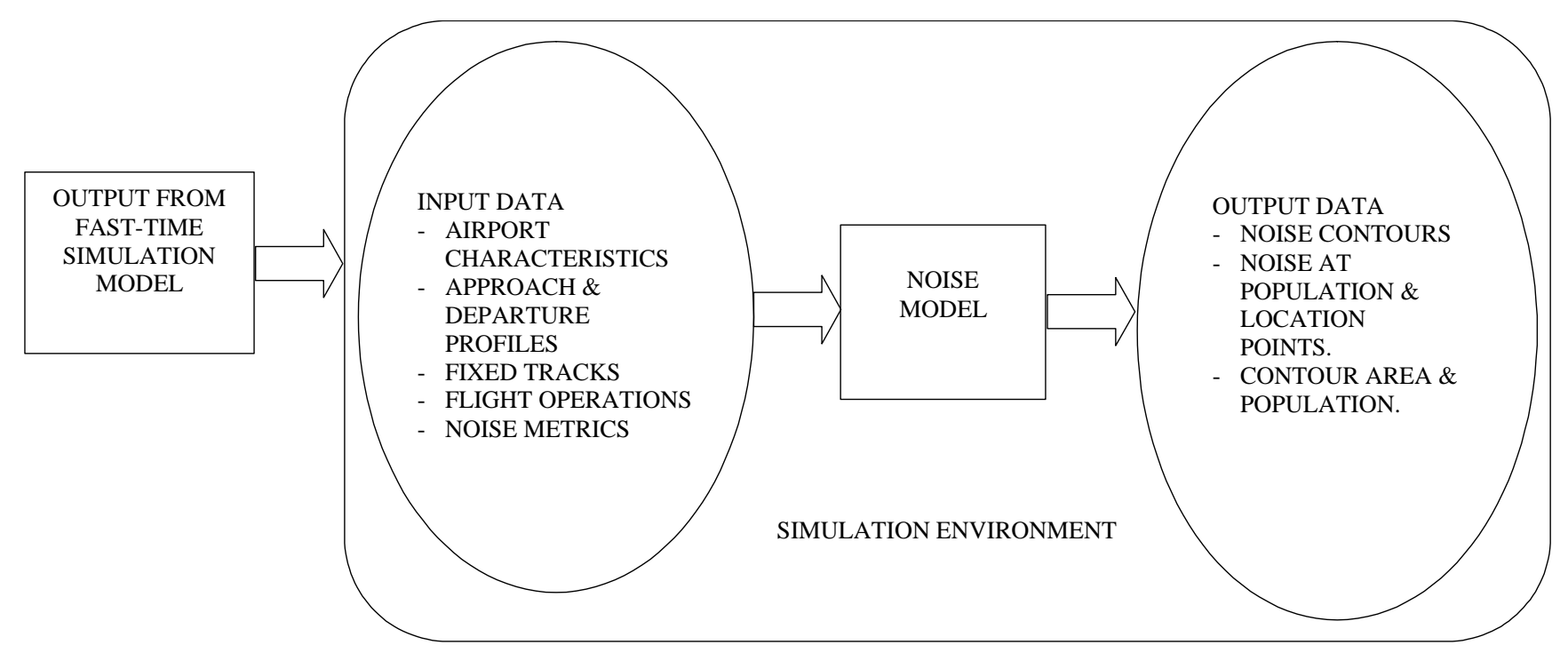

Figure 9. Block schematic of the noise prediction model. 


$$
L_{A E}=10 \log _{10}\left[\int_{d_{1}^{2} P^{2}(t) d t}^{P_{0}^{2} T} d B\right.
$$

The SEL is dependent on a number of factors namely the aircraft engine type, power, flap, airplane operating procedures, distance from location near the ground to the flight path of the airplane, and the topography as well as the weather conditions.

\subsubsection{A-weighted Maximum Sound Level}

The A-weighted maximum noise level (LAMAX) metric represents the maximum A-weighted noise level at an observers location, taking into account aircraft operations for a particular time period. For maximum-level metrics, the day, evening, and night multipliers are used as

$$
\mathrm{L}_{\mathrm{ASmx}}=\operatorname{Max}\left(W_{1} L_{\mathrm{MAX} 1}, W_{2} L_{\mathrm{MAX} 2}, W_{3} L_{\mathrm{MAX} 3}\right) \mathrm{dB}
$$

where, $\mathrm{L}_{\mathrm{ASmx}}$ is A-weighted maximum sound level (dB), $W_{1}, W_{2}, W_{3}$ are weights set to 1 to calculate maximum level during three time periods for day, evening, and night, and $\mathrm{L}_{\text {MAXI } 2,3}$ are maximum noise levels for day, evening, and night time periods.

\subsubsection{Day-night Average Sound Level}

The SEL for individual airplane operations is calculated first. Next, the average sound level produced by the cumulative effect of a series of different airplane operations, normally expressed in terms of Day-night Average Sound Level (DNL) averaged over a $24 \mathrm{~h}$ time period is calculated. $L_{d n}$ is $24 \mathrm{~h}$ time averaged $L_{A E}$, adjusted for average day sound source operations. The adjustment includes a 10$\mathrm{dB}$ penalty for aircraft pass-by occurring between 2200 and 0700 hours, local time (LT). $L_{d n}$ is computed as

$$
\begin{aligned}
L_{d n}= & L_{A E}+10 \log 10\left(1 \mathrm{xN}_{\mathrm{day}}+1 \mathrm{xN}_{\mathrm{eve}}+10 \mathrm{xN}_{\text {night }}\right) \\
& -49.37 \mathrm{~dB}
\end{aligned}
$$

where, $\mathrm{N}_{\text {day }}$ is the number of aircraft overflight between 0700 and 1900 hours (LT), $N_{\text {eve }}$ is the number of aircraft overflight between 1900 and 2200 hours (LT), $N_{\text {night }}$ is the number of aircraft overflight between 2200 and 0700 hours (LT), and 49.37 is the normalisation constant that spreads the acoustic energy associated with aircraft passby over a $24 \mathrm{~h}$ period.

$L_{d n}$ averaged over a year is termed as the yearly $L_{d n}$ and is used by FAA as a measure for acceptability or otherwise for land use compatibility ${ }^{10}$.

\section{NOISE CONTOURS FOR FLIGHT SCHEDULES FROM SIMULATION}

Using integrated noise mode $\mathrm{l}^{12}$ and simulation, aircraft noise has been predicted in the vicinity of HBIA for scheduled, domestic and international flights. Figure 10 shows HBIA with significant landmarks where noise level computations are important.

Figure 11 shows the noise contours in the vicinity of the HBIA highlighting DNL values as on $24^{\text {th }}$ November 2005. From the contour, it is seen that the third contour from the outermost has $65 \mathrm{~dB}$ noise level. The noise level acceptable for human habitation is outside this area. The unacceptable noise level area is approximately $6 \mathrm{~km}$ to the left of the runway, $6 \mathrm{~km}$ to the right of the runway, and $2 \mathrm{~km}$ to either side of the runway. It is also seen that some important places (like hospital) are in this unacceptable area at a distance of $2.2 \mathrm{~km}$ from the runway centre. As such, special sound insulation could be thought of for the inhabitants of such hospitals.

\section{NOISE CONTOURS FOR INDIVIDUAL AIRCRAFT FROM SIMULATION}

The noise contours in the vicinity of the airport due to individual aircraft noise have also been predicted. To predict this individual noise, the required input to the model are: (i) aircraft data, namely, description, number of engines, category, static thrust, maximum take-off weight (MTOW), gross takeoff weight (GTOW), maximum landing distance (in feet), and (ii) fixed-point profiles, thrust setting value with aircraft speed, altitude for climb or descent. 


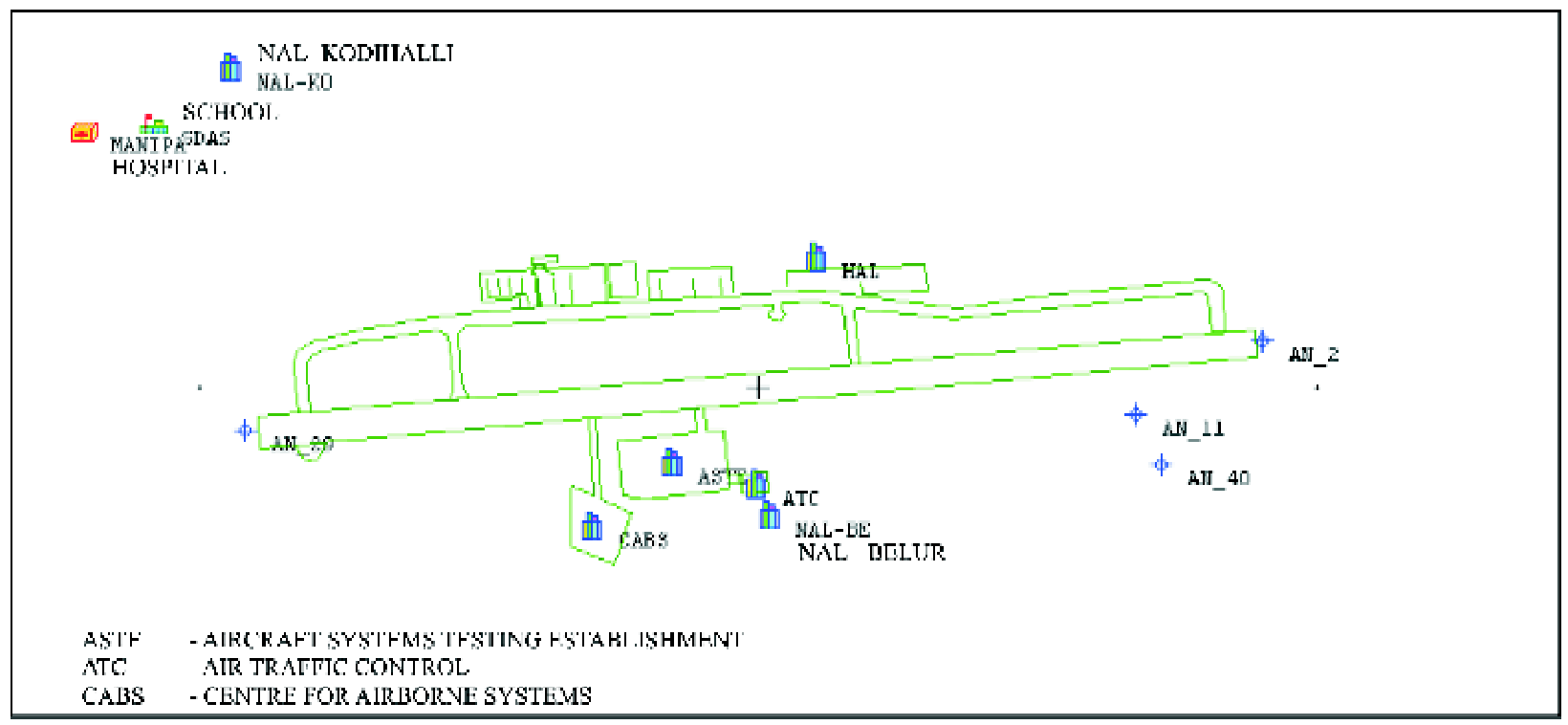

Figure 10. Vicinity of HBIA without noise contour.

SEL and LAMAX are the important noise parameters for estimating the noise due to individual aircraft. The prediction of output noise contributions due to individual aircraft noise of Boeing B747100, high performance fighter aircraft (HPFA) and light transport aircraft (LTA) has been carried out. It is found that the contribution to the maximum noise among the civil aircraft is from Boeing B747-100. The noise of high performance Fighter aircraft contributes to the maximum level amongst

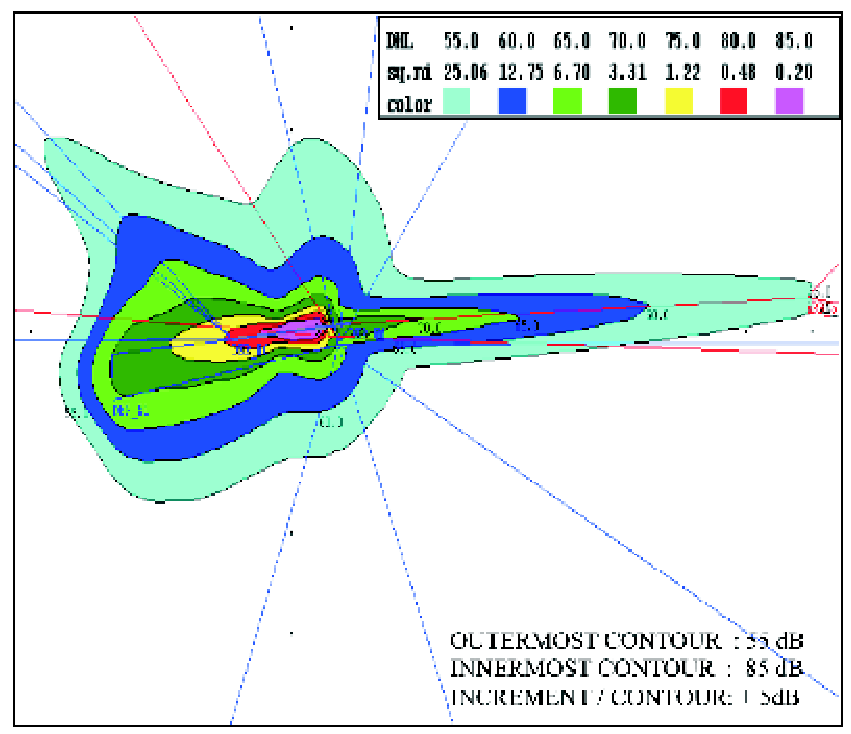

Figure 11. Aircraft noise contour-DNL at HBIA as on $24^{\text {th }}$ November 2005. all the aircraft types considered. Figures 12 and 13, show the SEL and LAMAX in the vicinity of HBIA due to Fighter aircraft. Figures 14 and 15 show SEL and LAMAX due to light transport aircraft.

A comparative study of increase in the noise levels for a busy day traffic as well as for individual aircraft has been carried out in the vicinity of HBIA for a busy day each in the month of May, August, and November 2005. Table 3 gives the comprehensive information on noise levels at the location points and populated places for a busy day traffic. This traffic includes the domestic and international flights.

Table 3 is a comparison of DNL at location points for the flight schedules as on $12^{\text {th }}$ May, $11^{\text {th }}$ August, and $24^{\text {th }}$ November 2005 in the vicinity of HBIA. From Table 3, one can see $2.8 \mathrm{~dB}$ increase in the noise level from May 2005 to November 2005. In seven months time, due to increased traffic, the level has gone up. A $3 \mathrm{~dB}$ increase amounts to doubling of the noise level. Also, National Aerospace Laboratories (NAL), Belur and CABS are having levels reaching nearly $80 \mathrm{~dB}$. These are concerning factors. Table 3 shows about $3 \mathrm{~dB}$ growth in noise level with traffic growth from May to August 2005 at Kodihalli 


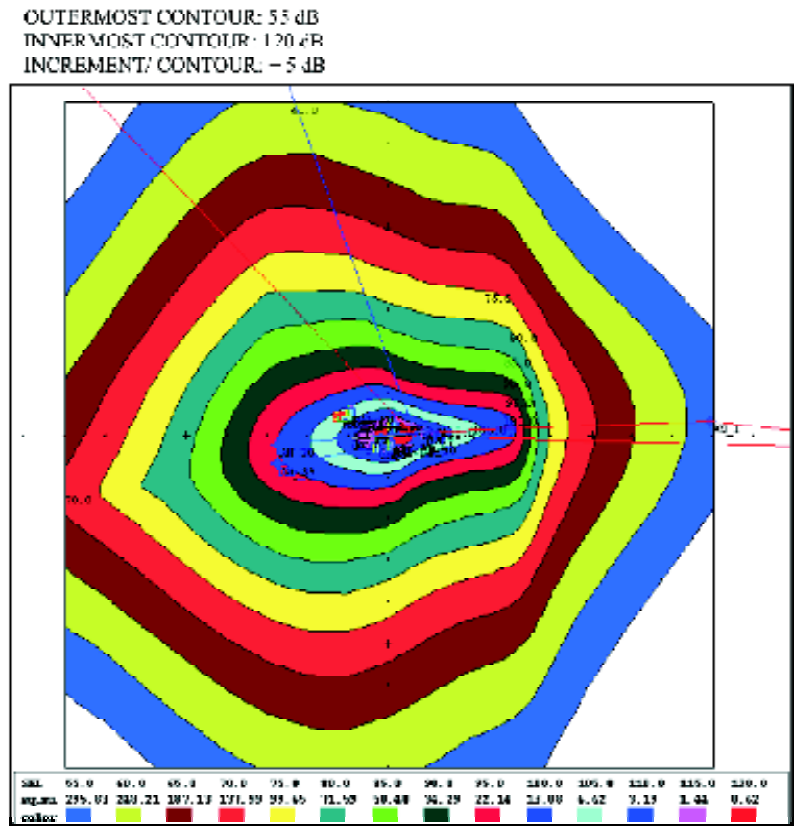

Figure 12. Individual aircraft (HPFA)-SEL noise contour.

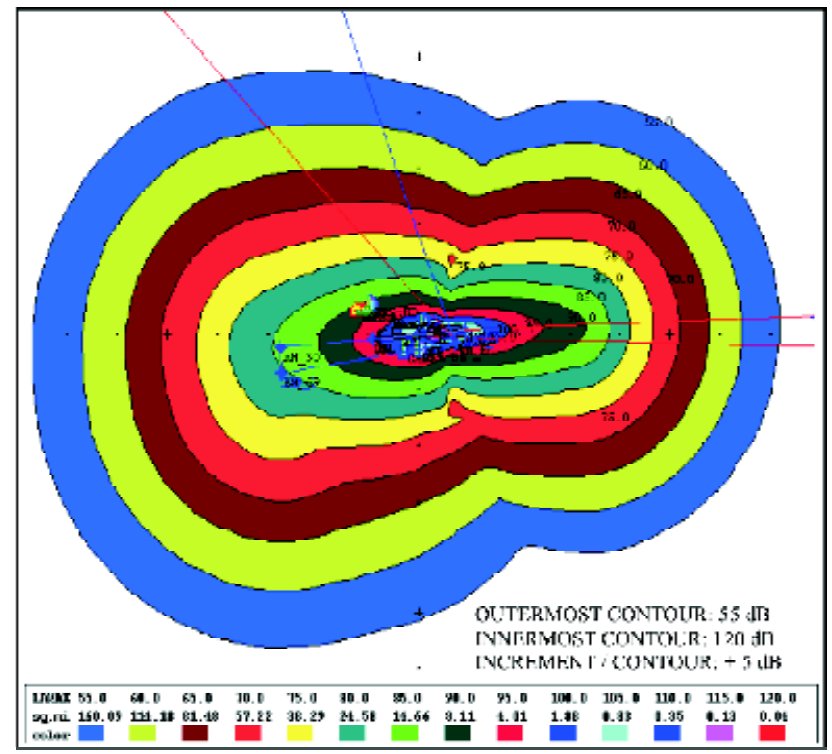

Figure 13. Individual aircraft (HPFA)-LAMAX noise contour.

and Murugeshpalya. From Table 3, the shaded portions show the values above $65 \mathrm{~dB}$ level.

Table 4 compares the SEL and LAMAX at the strategic location points due to individual aircraft namely B747-100, HPFA, and LTA in the vicinity of HBIA (This study includes only 1 Day time operation for departure and arrival. Night operation is not considered). It is observed that noise from military

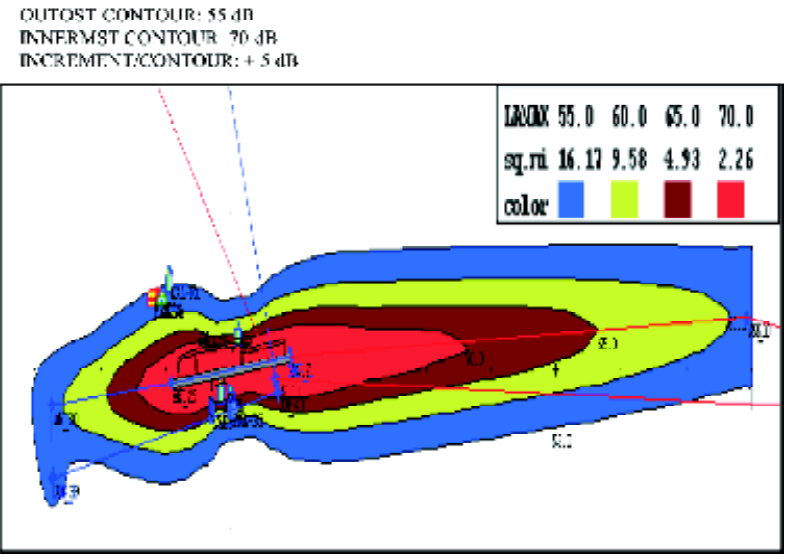

Figure 14. Individual aircraft (LTA)-SEL noise contour.

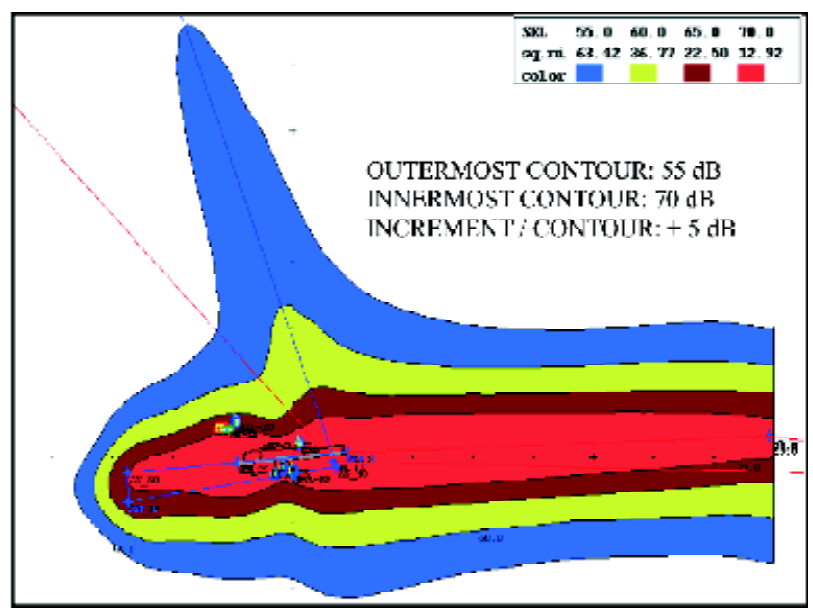

Figure 15.Individual aircraft (LTA)-LAMAX noise contour.

aircraft (HPFA) nearly touches the threshold of pain near a hospital in the surrounding area.

\section{CONCLUSIONS}

HBIA is hitting the limit of acceptable delay with assumed 10 per cent increase in traffic. As to the controller workload at HBIA during peak times, the capacity is hit, pushing the workload high. The noise contour prediction especially for military aircraft, is sounding a wake up call to the communities living in the vicinity of the airport. For any newly planned airport, it is necessary to accommodate the increasing air traffic by keeping the average delay at acceptable level. The appropriate agencies need to get together with aerodrome planners and use quantitative results of simulation for the benefit of all concerned. 
Table 3. Comparison between noise metric (DNL) at location points for the flight schedules as on 12th May 2005, 11 ${ }^{\text {th }}$ August 2005 and $24^{\text {th }}$ November 2005

\begin{tabular}{|c|c|c|c|}
\hline \multirow[t]{2}{*}{ Location points and populated places } & \multicolumn{3}{|c|}{ Point Metric DNL (dB) } \\
\hline & $12^{\text {th }}$ May 2005 & $11^{\text {th }}$ August 2005 & $24^{\text {th }}$ November 2005 \\
\hline ATC & 71.5 & 74.7 & 74.4 \\
\hline HOSPITAL & 63.5 & 65.7 & 66.3 \\
\hline NAL-KO & 60.5 & 62.7 & 63.2 \\
\hline SDAS & 62.7 & 64.9 & 65.5 \\
\hline ASTE & 69.4 & 72.4 & 72.3 \\
\hline HAL & 63.9 & 66.1 & 66.5 \\
\hline Touch down & 64.8 & 67.8 & 67.8 \\
\hline Take-off & 70.1 & 72.5 & 73.1 \\
\hline Murugeshpalya & 61.2 & 63.6 & 64.2 \\
\hline Kodihalli & 67.2 & 69.3 & 69.7 \\
\hline
\end{tabular}

Table 4. Comparison of SEL and LAMAX noise metrics at Location points for individual aircraft

\begin{tabular}{|c|c|c|c|c|c|c|}
\hline \multirow{3}{*}{$\begin{array}{l}\text { Location points } \\
\text { and } \\
\text { populated places }\end{array}$} & \multicolumn{6}{|c|}{ Point Metrics in dB } \\
\hline & \multicolumn{3}{|c|}{ SEL } & \multicolumn{3}{|c|}{ LAMAX } \\
\hline & $\begin{array}{c}\text { B741 } \\
\text { Boeing } \\
747-100\end{array}$ & HPFA & LTA & $\begin{array}{c}\text { B741 } \\
\text { Boeing } \\
\text { 747-100 }\end{array}$ & HPFA & LTA \\
\hline ATC & 108.3 & 118.6 & 76.8 & 104.5 & 103.0 & 70.4 \\
\hline HOSPITAL & 88.8 & 110.6 & 66.8 & 75.7 & 96.2 & 54.6 \\
\hline NAL-BE & 114.9 & 117.4 & 82.6 & 114.5 & 101.5 & 78.9 \\
\hline NAL-KO & 86.4 & 109.5 & 65.4 & 72.1 & 94.4 & 52.6 \\
\hline SDAS & 88.4 & 110.9 & 66.8 & 75.2 & 96.3 & 54.5 \\
\hline ASTE & 103.8 & 120.9 & 73.4 & 98.2 & 106.0 & 65.2 \\
\hline CABS & 112.0 & 119.7 & 80.0 & 109.8 & 105.1 & 74.9 \\
\hline HAL & 95.1 & 116.4 & 70.1 & 82.7 & 100.2 & 53.9 \\
\hline Touch down & 97.4 & 109.0 & 73.8 & 90.2 & 98.9 & 60.6 \\
\hline Take-off & 99.2 & 137.3 & 74.8 & 88.0 & 129.8 & 63.8 \\
\hline MURGESHPALYA & 88.7 & 112.3 & 68.6 & 76.5 & 96.3 & 58.1 \\
\hline KODIHALLI & 92.2 & 107.0 & 69.6 & 80.5 & 91.8 & 58.0 \\
\hline
\end{tabular}

\section{ACKNOWLEDGMENTS}

The authors would like to acknowledge Mr S.R. Iyer, HAL Bangalore International Airport, for giving valuable inputs to the studies.

\section{REFERENCES}

1. Madhuranath, Padma; Lathasree, P. \& Senthil kumar, T. Simulation and analysis of Indian Air Traffic. NAL PD FC 0514, October 2005.

2. Madhuranath, Padma \& Raol, J.R. Ed, Proceedings of NAL-DLR Seminar on Traffic Management. NAL-SP-0211, May 2002.
3. ATAC. SIMMOD PLUS! Reference manual.

4. US Department of Transportation, FAA. Airport capacity and delay. Advisory Circular, AC/150/ 5060-5, 9-23-83.

5. Lathasree, P. \& Christ, Thomas. Air traffic analysis for Indian scenario using fast-time simulation models. In Proceedings of Aerospace Technology Challenges in the Millennium, 1516 December 2003, AeSI, Hyderabad.

6. Alexander, T. Wells. Airport planning and management. Ed.3. McGraw-Hill Publications, 1986., McGraw Hill, USA. pp. 178-79. 
7. US Department of Transportation, FAA. Airport capacity handbook. SRDS Report No. RD-68-14, June 1969.

8. Majumdar, Arnab. ATM capacity analyses and their safety implications with case studies.In Proceedings of CITAT-05, IIT Mumbai, January 2005.

9. Airport tools. Visual SIMMOD software reference manual.
10. US Department of Transportation, FAA. Noise control and compatibility planning for airports. Advisory circular AC 150/5020-1, August 5, 1983.

11. Procedure for the calculation of airplane noise in the vicinity of airports. Report No. SAE AIR 1845, March 1986.

12. Office of Environment and Energy, FAA. Integrated noise model (INM), version 6.0, Technical Manual. January 2002.

\section{Contributors}

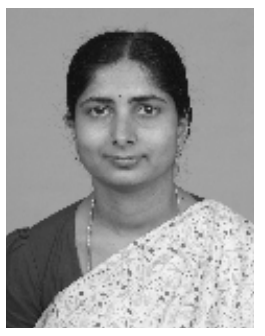

Ms P. Lathasree obtained BTech in 1989 and ME in 1992 from Nagarjuna University, Guntur, and Bharathiar University, Coimbatore respectively. Presently, she is working on air traffic management and simulation, LCA and SARAS simulator projects. Her research areas of interest are: Air traffic management, modelling, simulation and control of aircraft.

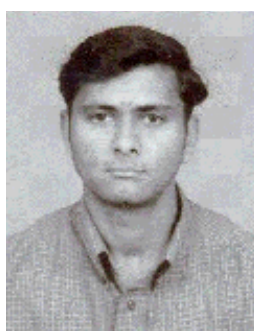

Mr T. Senthilkumar received BE (Elect \& Commu Engg) Degree from Madurai Kamaraj University, Madurai, in 2002 and MTech in Advanced Communication systems from SASTRA University, Tanjore in 2004. His areas of interests are on air traffic management: modelling and simulation of airports, prediction of aircraft noise near airports, modelling airport capacity studies and aircraft Conflict detection and resolution $(C D \& R)$. His major contributions are towards the 3-D airport visual simulator facility. He is a member of IEEE and AIAA.

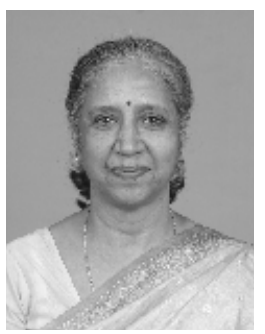

Ms Padma Madhuranath obtained Masters degree (Electrical Engg) from the University of Aston, UK. She has four years of professional experience as Design and Development Engineer in the UK. She is working as a Scientist at the National Aerospace Laboratories from 1977. She was a Guest Scientist at DLR in Germany from Oct 1985-May 1986 under CSIR-DLR Collaboration. She has received several awards for outstanding performance in flight simulation activities. Her R\&D areas are: Aircraft flight simulation and modelling, simulation and analysis of air traffic management and acoustics. 